\title{
AN AGENT BASED MODEL FOR LAND USE POLICIES IN COASTAL AREAS
}

\author{
Shima Nabinejad ${ }^{1}$ and Holger Schüttrumpf ${ }^{2}$
}

Reducing the probability of flooding by flood defence structures might not be successful without appropriate actions taken in order to mitigate flood damages. Moreover, success depends on actions at both governmental and individual levels. Therefore, farmers as the inhabitant of flooding areas may contribute to flood management in terms of land use policies which lead to communication, human interaction, and adaptation. However, these social behaviors have not taken into account in flood management studies due to their complex nature and human has been only considered as the receptor of flooding without paying attention to multiple feedbacks over time horizons with a dynamic approach. In our study, we overcome this deficiency by employing Agent Based Model (ABM) of land use policy in flood risk management and address challenges regarding social interactions in this research area. Our Agent Based Model includes perspectives from engineering, decision making, and socio-economics allowing to model human-flood interactions. In this model, farmers are considered as individuals whose decisions depend on climatic conditions, crop yields, costs and prices, flood damage, personal risk perception, and their social interactions. This is achieved by integrating three main modules including hydrological module, flood analysis module, and decision making module in the frame of Agent Based Model. This paper has shed some light on main concepts of our Agent Based Model including the developed methodology, main modules, required information, and initial results. It also summarizes the components of the modules and the governed interactions.

Keywords: Agent Based Modeling, land use change, coastal regions, and human-flood interaction

\section{INTRODUCTION}

Recently, extreme meteorological events such as flooding and storm surges in coastal areas have been increased due to climate change and caused economic damages and loss of life [1] [2]. On the other hand, coasts are attractive settling grounds for humans for providing fertile land and possibilities for trade and transport. In light of this situation, coasts may be regarded as pathways of flooding as far as coastal habitants such as farmers offer some coastal protections in terms of land use policies and of course these habitats are receptors whose survival or modification depends on this natural hazard.

Therefore, humans as the receptor of flooding has interaction with flood and their decision before, after and during floods may reduce flood damages. This human-flood interaction can be regarded as non-structural measures such as land use planning which result in communication among habitants. It is, therefore, essential to consider social behaviors in flood risk management (FRM) which is often too complex for standard mathematical approaches.

Flood risk management may contribute in decreasing risk by mitigation and adaptation which refers to actions taken for declining the probability of flooding like coastal structures and the responses as land use policies for damage reduction, respectively [3]. Previous studies have been built upon models such as Source-Pathway-Receptor-Consequence (SPRC) model in flood risk management of coastal areas. Despite their benefits, they have not included humans as an important element resulting in risk perception, communication, and learning process. It is important due to unavoidable role of humans in decision making which in turn results in complex social behaviors.

Overall, the simple SPRC model should be modified with complex interactions and multiple feed backs between pathways and receptors over time horizon.

It seems, therefore, reasonable to develop a comprehensive approach and adaptive Flood risk management regarding land use policies to understand important entities, to consider their interactions and to investigate their impacts over time. The aim of this study is to discuss the concepts of developed ABM which include farmers, as the central decision makers of land use change in flooding area to modify the unidirectional chain in SPRC model. Our ABM also seeks to assess the influence of future prices, weather conditions and flood damages on farmers' risk perception and crop policies and how these influence flood losses.

The paper starts with the study area, which will then be continued by methodological approaches including modules of research, applied methods and required data. Finally, the overall perspective of the research will be discussed and concluded.

\section{Study area}

The Halligen in the Northfrisian part of the UNESCO-World Natural Heritage Wadden Sea will be investigated as one of the case study due to the very exposed situation as shown in Figure 1 . The

\footnotetext{
${ }^{1}$ Institute of Hydraulic Engineering and Water Resources Management (IWW), RWTH Aachen University, Mies-vander-Rohe Straße 17, Aachen, NRW, 52056, Germany

2 Institute of Hydraulic Engineering and Water Resources Management (IWW), RWTH Aachen University, Mies-vander-Rohe Straße 17, Aachen, NRW, 52056, Germany
} 
population is about 300 who are living on a total area of $21.1 \mathrm{~km}^{2}$. Climate change has caused sea level rising and in the time of flooding, the citizens of the Halligen are surrounded by water. The inhabitants of these small marsh islands have built their houses on 37 dwelling mounds to protect themselves during storm events since there are no dikes as coastal structures and these mounds are the only places which are not inundated in the time of flooding on the islands. In addition to the tidal channel system equipped with tidal gates, shallow summer dikes prevent the area from inundation during moderate high tide events. The Halligen is a place for salt marsh plants as well as migratory birds which make them more important from ecological perspectives. Taking cultural and environmental features into account, Halligen is also an attractive area for tourists.

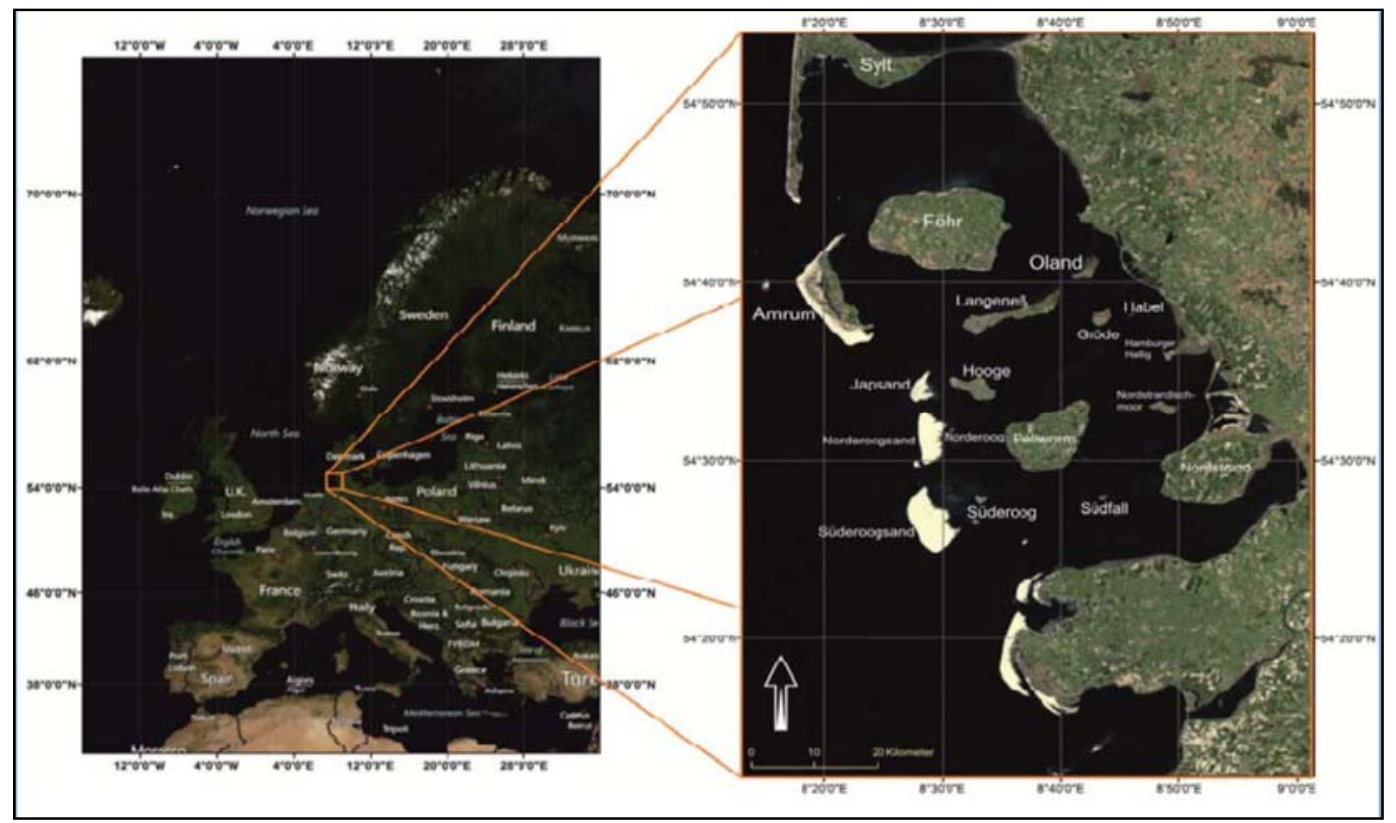

Figure 1. Hallig Islands in Northern Germany

The project ZukunftHallig has been developed by IWW, RWTH Aachen University to design new coastal protection and management strategies in cooperation with a sociological partner. Data and results of this project as well as the interviews performed by the sociological partner are used in defining the agents.

The North Frisian Island Pellworm is another study area located in the German Wadden Sea National Park as shown in the figure 2.

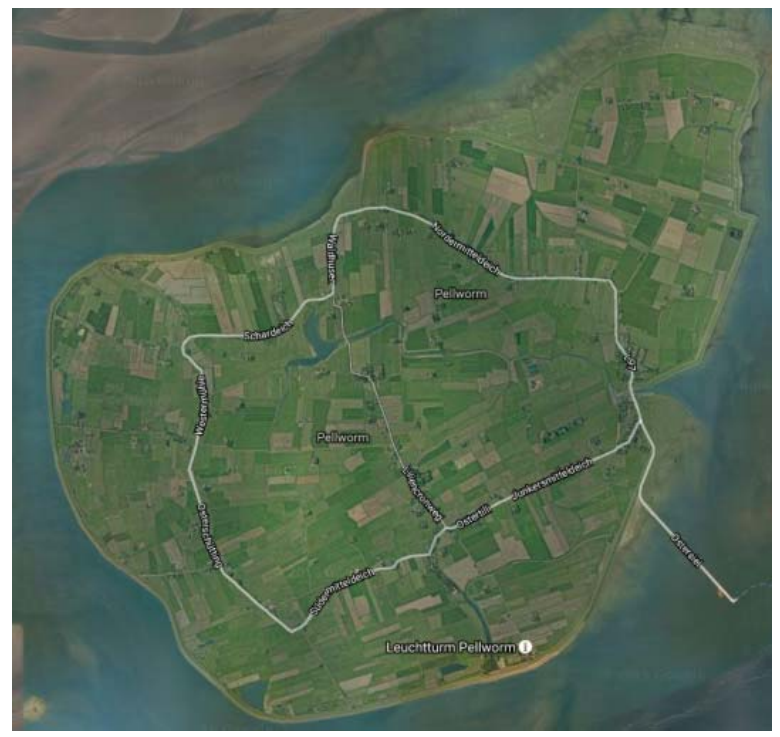

Figure 2. Pellworm Island in Northern Germany 
This island is a municipality of the Schleswig Holstein state and adjacent entities are Nordstrand, Hallig islands and Eiderstedt. 1158 inhabitants populate the area of about $37 \mathrm{~km}^{2}$. The distance between the northern and southern part is approximately $7 \mathrm{~km}$. Its mean height is approximately $0.23 \mathrm{~m}$ above sea level and $28 \mathrm{~km}$ of sea dikes up to a height of $8.80 \mathrm{~m}$ protect the island located in mudflats. The earliest medieval settlements were found originating from the 9th century. During two devastating floods in 1362 and 1634, in which thousands of people died, Pellworm Island was separated from Alt-Nordstrand. In the beginning of the 19th century, outer dike was constructed to secure the island against further floods and storm surges. Today, inhabitants of Pellworm Island are highly dependent on a fairy connection and sea pipes delivering goods, electricity and drinking water. The main economic sectors are agriculture and tourism and most of the island's area is covered by agricultural land.

\section{METHODOLOGY}

Although, previous studies based on flood risk management have provided decision makers with valuable insights, they cannot address the mentioned challenges of social behaviors due to humans' interaction. Therefore, it is essential to equip flood management with social techniques such as System Dynamic, Cellar Automata and Agent Based Modeling, as represented in table 1.

Table 1. Comparison between social simulation techniques [4]

\begin{tabular}{|c|c|c|c|c|}
\hline Technique & Number of level & Communication & Complexity & Number of agents \\
\hline System dynamics & 1 & No & Low & 1 \\
Microsimulation & 2 & No & High & Many \\
Learning models & $2+$ & Maybe & High & Many \\
Agent Based Modeling & $2+$ & Yes & Low & Many \\
Cellular automata & 2 & Yes & Low & Many \\
Multilevel simulation & $2+$ & Maybe &
\end{tabular}

In this table, techniques with the number of level more than one have the capability to model the interactions between individual and society and in turn emergent phenomena. Among these techniques, Agent Based Modeling is the most appropriate one since it can model high levels of complexity as well as communication among individuals which provides new insights into policy analysis and practical applications in coastal areas.

\section{Agent Based Model (ABM)}

A major method for addressing challenges regarding social interaction is Agent Based Modeling which allows exploration of interactions between social and natural elements over time [5]. Agent Based Modeling is a new technique for understanding how the dynamics of the complex systems arise from the characteristics and behaviors of autonomous and interacting computational objects, called agents. In comparison with “top-down” modeling, Agent Based Modeling provides a "bottom-up” approach, where behaviors are captured at agents’ level [6]. Agents are autonomous, interacting computational objects, situated in space and time, with unique attributes.

Agent Based Modeling was developed as a concept in the late 1940s and it became widespread after availability of powerful computers. Agent Based Modeling has been used in biology, political science and social networks and it is well suited to Flood Risk Management considering human experience, learning and responses.

\section{Toolkit for Developing Agent Based Model}

The programming language in this study is NetLogo since it is freely available and includes a set of library as well as a graphical interface [7]. It was designed by Uri Wilensky in 1999 and is well suited for modeling social behavior in terms of turtles, patches, links, the observer and instructions governing agents' behaviors [8]. NetLogo has been used in different research areas including biology, physics and chemistry, mathematics and computer science, and economics. An example of NetLogo implementation is Wolf-Sheep Predation model [9]. Moreover, there are applications for house hold water use [10] and a predator-prey model in biology [11]. Netlogo also has been applied in immunology for formulation the disease mechanisms [12].

\section{Land Use and Agent Based Modeling}

The ABM in this research is based on individual farmers living in the coastal regions who may be suffered by flooding in terms of flood damages. The farmers choose cropping pattern on their field as functions of climatic condition, crop production, costs and prices, risk aversion and flood loss. 
Figure 3 presents the general flowchart of the research methodology. The expected results are to calculate and make policies for land use in term of the farmers' behavior and decreased flood damages due to strategies and agents' interaction over time which cannot be met in the traditional methods.

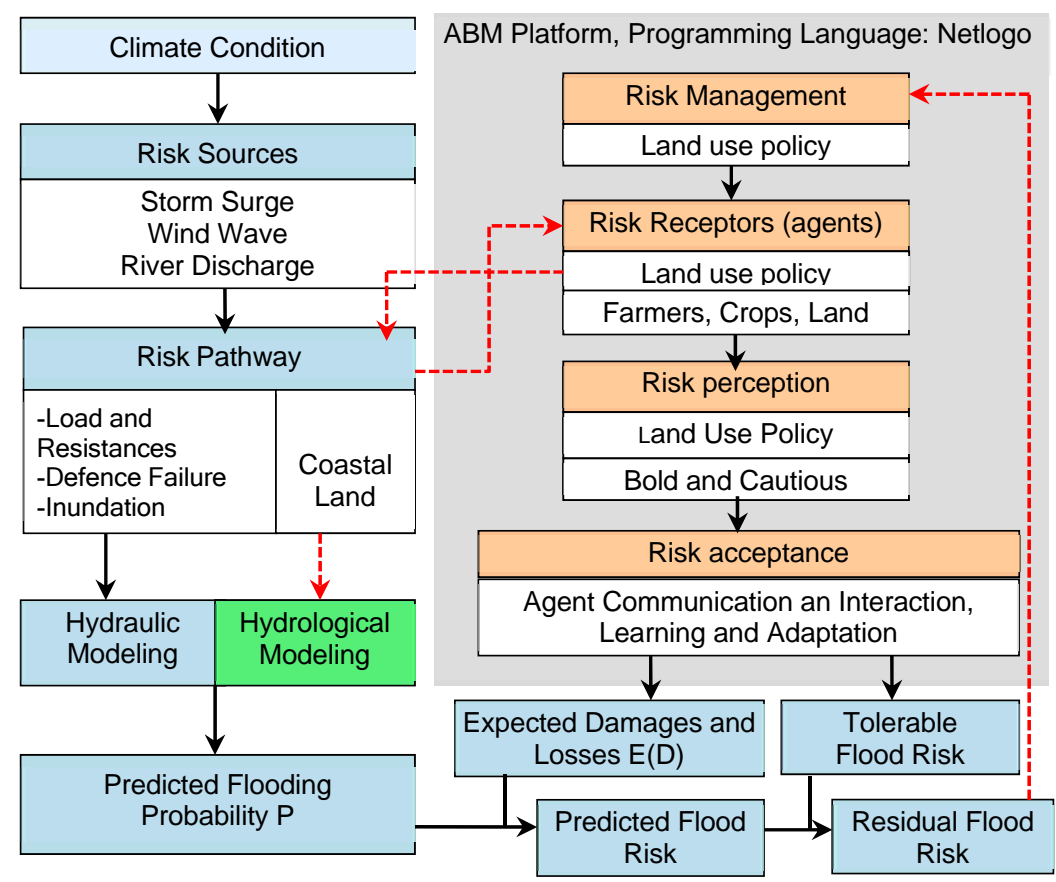

Figure 3. Flowchart of the research methodology

All things considered, an ABM for land use planning in flood management is developed which consists of three integrated modules: 1) hydrological module, 2) flood analysis module, and 3) decision making module, as depicted in figure 4.

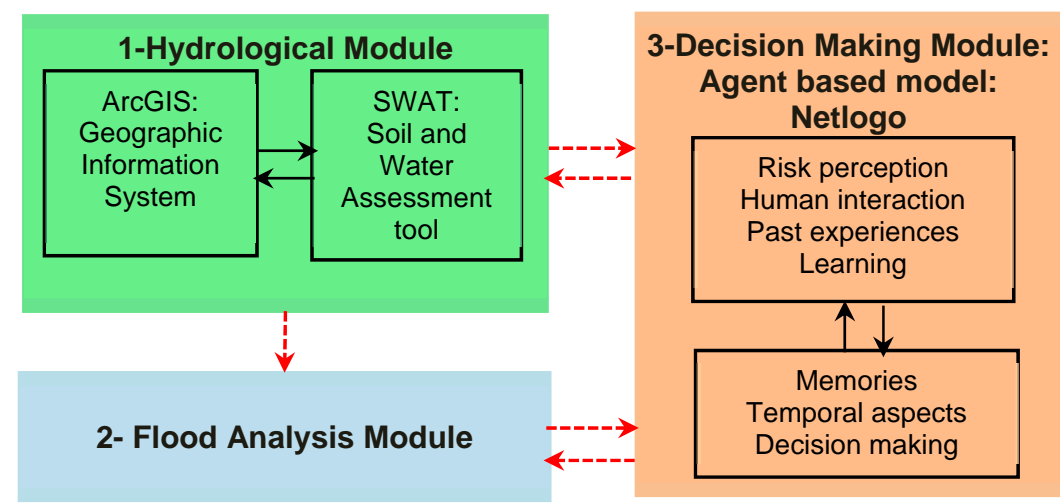

Figure 4. Submodels of the ABM for land use planning in flood management

The hydrological model generates runoff and crop yield data as input to the other modules. In flood analysis module, the hydrodynamic simulation, flooding probability analysis, and damage estimation are defined in combination of submodules to compute flood damages and associated risk. To investigate human response over time in flooding area, the decision making module is linked to two other modules to compute farmers' management decision in each time step.

To build an ABM, a land use scenario is developed and agricultural agents are identified due to the flood risk strategies. Then, the governing rules between the agents are designed. In each time step, future prices according to a forecasting algorithm and weather conditions become available from public sources or agents' interaction. Those decisions feed back to hydrological module and flood risk analysis module to evaluate crop yields and flood losses in the next time step and human-flood interactions are adapted over time. Hence, the integrated model is powerful in terms of human risk perception, flood experiences, and social interaction in addition to merits of pure Flood Risk Management. 
Individual farmers with heterogeneous attributes and behaviors make decisions about cropping pattern in the physical and social environments. In other words, they have interaction with both environments and their decisions depend on them. Moreover, they influence these environments over time which presents dynamics of coupled human and natural systems.

Physical environment includes physical factors that affect crop production in growing seasons as follows:

- Climatic conditions such as precipitation, air temperature, relative humidity, solar radiation, and wind speed

- $\quad$ Properties of land such as soil type, soil properties, and land management practices

Social environment consists of the elements which play roles in human decision making and can be classified as follows:

- Farmers' social network such as their neighbors, friends and family

- $\quad$ Prices in markets such as crop prices, farm machinery costs, cost of fertilizer, payment of labor, and so on.

- Individual perceptions such as past experiences of flooding, risk associated with flood events, and expectation

In our conceptual model, farmers interact with these environments and take decisions. The components of these environments form the interactive elements of integrated modules in the unique Agent Based Model.

\section{Hydrological Module}

This module provides the decision making module with actual crop yields as well as flood risk analysis module with runoff and crop yield by applying ArcSWAT2012 which is an ArcGIS extension of SWAT model. Preparing various kinds of inputs, crop yields and runoff are computed for each time step based on characteristic of physical environment including climatic condition of the area, soil and topography condition and land use.

The Soil and Water Assessment Tool (SWAT) [13] is a hydrological watershed model developed by Dr. Jeff Arnold for the U.S. Department of Agriculture (USDA) Agricultural Research Service (ARS). The recent graphical interface of SWAT is ArcSWAT 12, an extension in ArcGIS 10.0.

The ArcSWAT model is able to predict long-term effects of land management practices, land cover and land use changes on crop yield, hydrological responses, and water quality components in large complex watersheds on a daily time step [14].

Figure 5 illustrates modeling steps of ArcSWAT in sequential order. As shown, after set up preparation, it is calibrated by SWAT-CUP and the calibrated parameters are applied for the whole simulation with ArcSWAT.

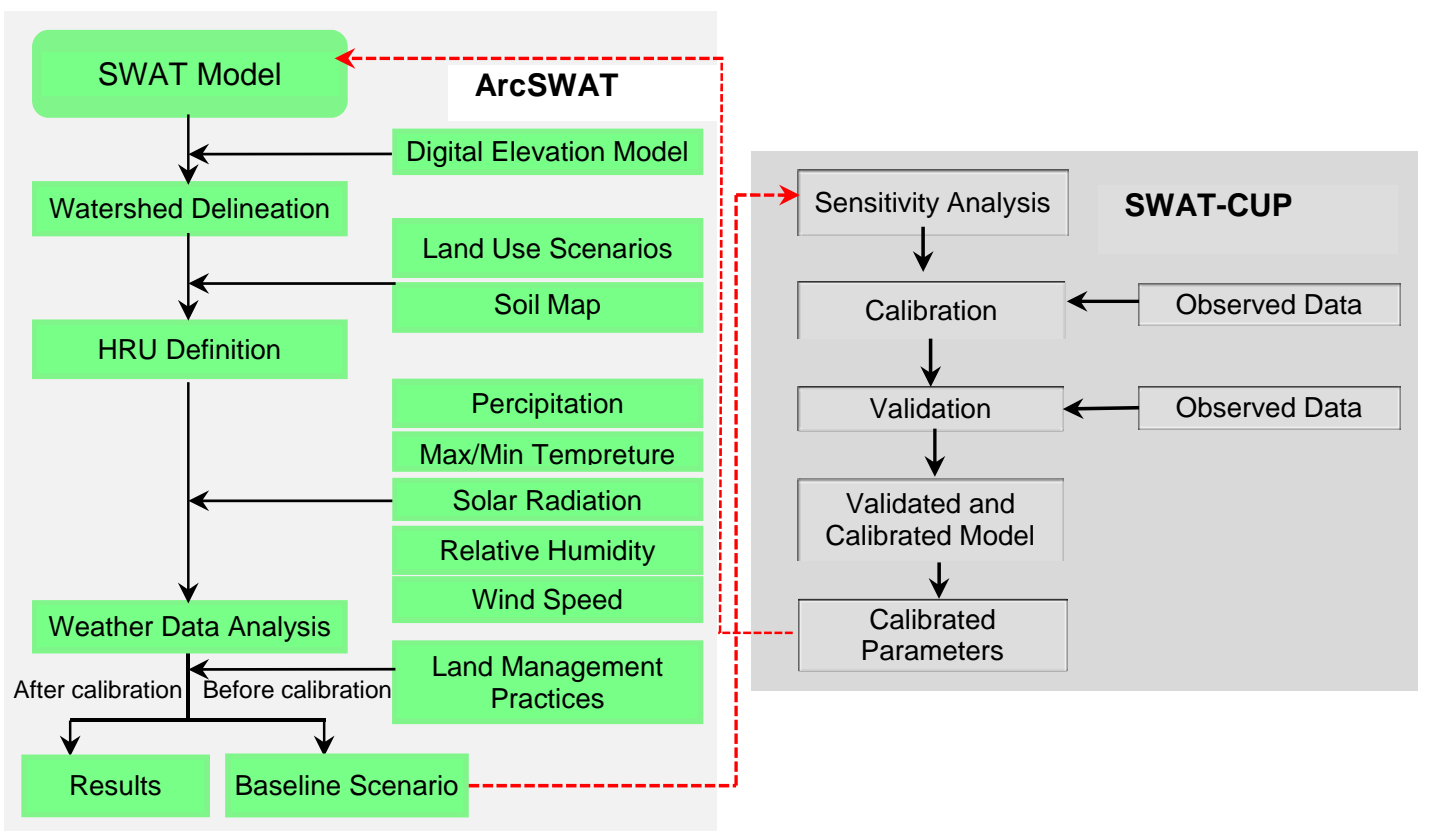

Figure 5. Modeling steps in a calibrated- validated ArcSWAT model 
To model the crop growth as well as water cycle, various spatial data including topography, vegetation, soil properties, weather and optionally land management practices are required by ArcSWAT, as a physically based model. Climatic variables consist of daily precipitation, minimum and maximum air temperature, solar radiation, wind speed and relative humidity. Data of further land management practices, plant growth, pesticides, fertilizers and urban areas are provided in databases within ArcSWAT [15]. Therefore, in each time step crop yields and runoff can be calculated with high accuracy.

\section{Flood Analysis Module}

This module is linked to decision making modules to equip farmers with the ability to consider past flood experience, flood risk perception and damages in decision making in addition to properties of physical environment. So, farmers will be aware of the losses of flood as the costs of their decision in the previous time step. For computing flood damages, the modular program package PROMAIDES (Protection Measure against Inundation Decision Support) is applied, as presented in figure 6.

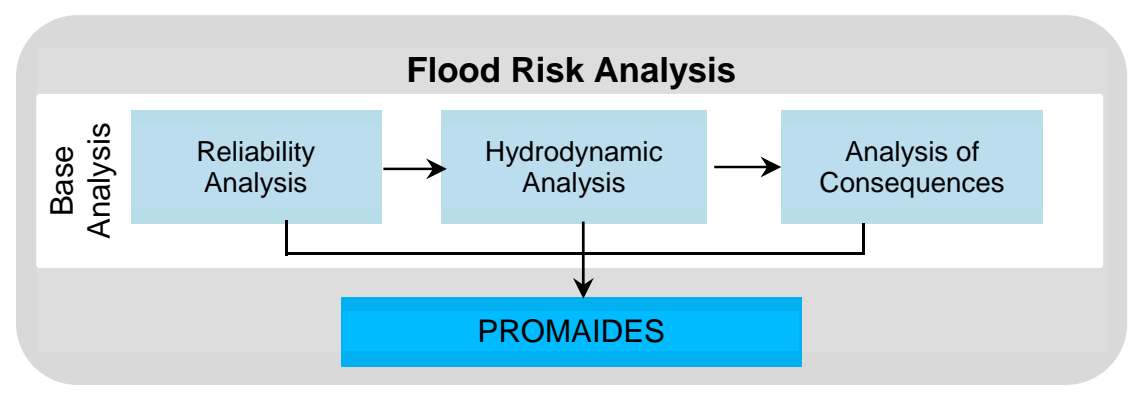

Figure 6. Modular program package PROMAIDES and the implemented modules

The modular-designed decision support system PROMAIDES has being developed at the Institute of Hydraulic Engineering and Water Resources Management (RWTH Aachen University) for river basin areas [16] which was then extended for flood risk calculation in coastal regions [17].

This software integrates three different submodels as follows:

- Reliability analysis (FPL submodel): The goal of Reliability analysis is to quantify in which probability a flood defence structure is failed.

- Hydrodynamic analysis (HYD module): This module determines the flow velocity and water level of the inundated area due to each flood event. That is, the flood event is transformed into hydraulic variables taking the morphological characteristics of the regions into account.

- Consequence analysis (DAM module): In the last step, the calculated hydraulic variables of the flood event in the inundated area with specified land use are transformed into consequences for the people and economic values located in the inundated areas of the hinterland.

- $\quad$ Risk analysis (RISK module): Considering the region as a system, total flood risk is computed as the combination of results of the other modules.

\section{Decision Making Module}

The standard farmer decision making is based on the fully rationality in which farmers try to maximize their goal (mostly economic goals). The main assumption is that the main agents of the system are perfectly rational goal maximizers who access to full information about prices and markets. However, in decision making process, different levels of knowledge may be available for each individual that forms different rationality among humans such as bounded-rationality and full-rationality. Although, traditional decision making approaches have focused on the rational agents who maximize their goals, it does not model the real decision making.

Moreover, Farmers are bounded rational agents whose decision making are based on crop yield, profit, past experiences, neighbors' decisions, and risk perception toward climate-related events such as floods and these make farmers deviate from goals' maximization to cognitive decision making.

Therefore, some new approaches should be applied which can equip bounded rational agents with different decision strategies more than pure maximizations. In our research, agricultural agents engage in various cognitive process based on their individual perceptions which is heterogeneous among farmers. Figure 7 illustrates the decision making module and its components in combination with two other modules. Being aware of flood damages and crop yields, each individual farmer make decisions for the next time step which are then fed into two other modules as land use policies. 


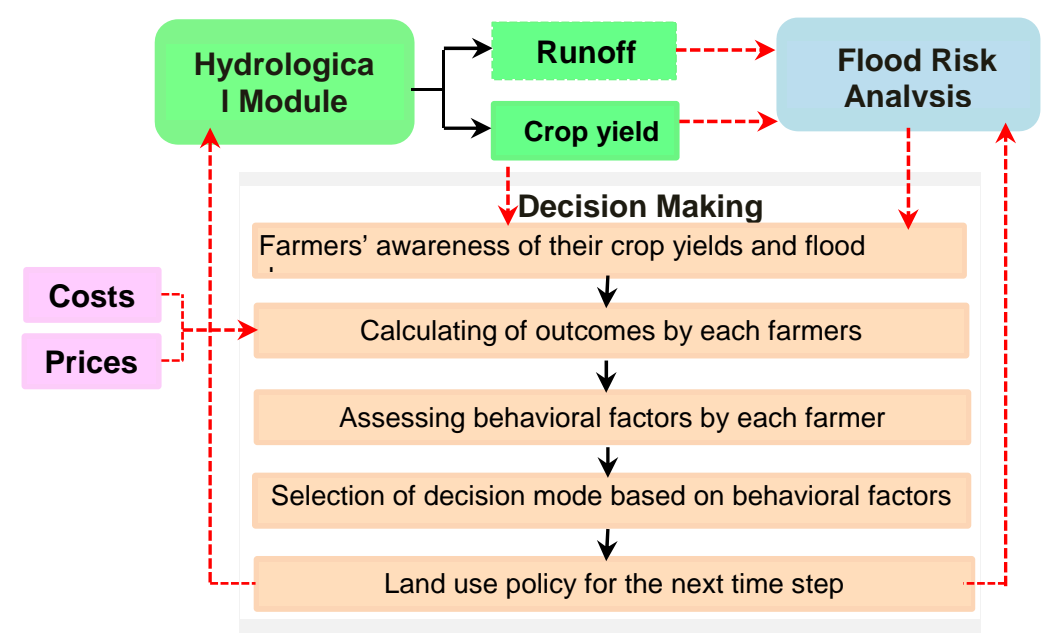

Figure 7. Modeling steps in decision making module

Input Data

Each of the three modules requires their own input data for preparing their setup. Some additional data are also essential for calibration of the hydrological module.

Topographical Data: A Digital Elevation Model (DEM) of the study area was obtained from the State Department of Agriculture, Environment and Rural Areas of Schleswig-Holstein. The topological data is used as the input of hydrological module as well as flood risk analysis module.

Geological Data: The State Department of Agriculture, Environment and Rural Areas of SchleswigHolstein provided a detailed soil map for the study area. Soil map is fed into hydrological module for computation of crop yield.

Land Use Data: The State Department of Agriculture, Environment and Rural Areas of SchleswigHolstein also provided a land use map of the study area for implementing the setup of hydrological module and flood risk analysis module. However, this land use map is updated in each time step for both modules as the result of farmers' decision making on cropping pattern in the previous time step.

Land Management Data: Seeding and harvesting dates were obtained from the agrometeorological section of Germany's National Meteorological Service (DWD) in .txt files which are used as the input data of hydrological module.

Meteorological Data: Weather information (CDC, 2016) was obtained from the public FTP server of Germany's National Meteorological Service (DWD). It consists of daily precipitation [mm], max/min temperature $\left[{ }^{\circ} \mathrm{C}\right]$, relative humidity $[-]$, solar radiation $\left[\mathrm{MJ} / \mathrm{m}^{2} / \mathrm{d}\right]$, and wind speed $[\mathrm{m} / \mathrm{s}]$. hydrological module requires climatic data in order to compute crop yields.

Hydrological Data: Calculated real evapotranspiration values for the study area are also obtained from Germany's National Meteorological Service (DWD) based on which the calibration and validation of the hydrological module are done.

Flood Scenarios Data: This is one of the boundary condition for hydro-numerical simulation for flood analysis module which is created based on the historical data.

Geometry and Material of Flood Protection Measures: In order to perform reliability analysis for flood analysis module, properties of flood defence structures should be defined by which the probability of the failure is quantified.

Damage functions and stock values Data: These are fed into flood analysis module to calculate economic damage for the selected flood scenarios. For this objective, mean stock values as well as the land use map are essential.

\section{RESULTS}

Here we present some results as examples of interaction between three above-mentioned modules for Pellworm Island. The input data have been prepared in the appropriate format and fed into the related individual module. In this paper, three out of various flood scenarios are selected which differ in breach location. A continues breach development is implemented within PROMAIDES and the maximum 
possible width of breach is $150 \mathrm{~m}$. The breach is located in distance of $160 \mathrm{~m}, 205 \mathrm{~m}$, and $239 \mathrm{~m}$ from the defined initial point and as a result scenario 1, scenario 2, and scenario 3 are built respectively.

The storm surge hydrograph with the 100 -year return period is considered as the boundary condition for the hydrodynamic simulation of flood risk analysis, as illustrated in figure 8.

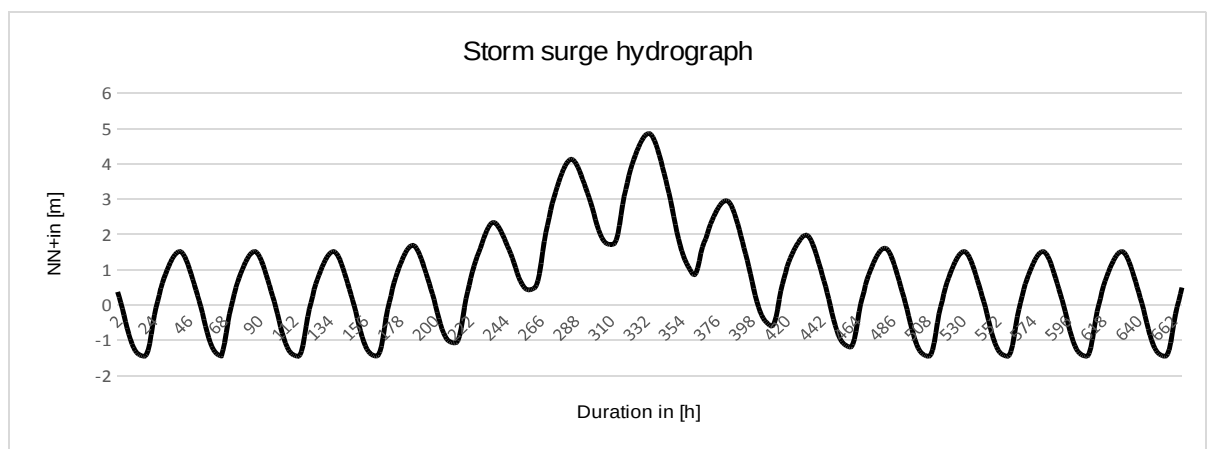

Figure 8. Storm surge hydrograph with a 100-year return period

The second important input data for flood analysis module as well as hydrological module is digital elevation model (DEM). The grid size of DEM for hydrodynamic analysis is 50x50m while a 2x2m cell size was used for the hydrological module for more accurate simulation.

Land use data is another input of flood analysis module. Since farmers are the central decision makers of this research, agricultural land use is considered as the input map for further analysis. That is, the generated land use data of hydrological module which includes yields of each agricultural field, is transformed to land use raster with cell size of $25 \times 25 \mathrm{~m}$ to be fed into flood analysis module. To calculate the economic damage for the selected flood scenarios, the agricultural land use is classified based on crop types. It should be noticed that in comparison to other types of land use coverage for which the relative damage varies for various water depths, crops are damaged totally (100\%) if the field is inundated.

Taking all input data into account, the flood risk analysis is performed for three mentioned scenarios. Economic damages and inundation depths which are calculated in flood analysis module are then called to decision making module and each individual farmer chooses his crop pattern for the next year according to his economic damages, behavioral profile, and flood damages experienced by neighbors in his social networks.

For better comparison, figure 9, 10, and 11 represent inundated areas, farmers suffered from flooding as well as condition of their neighbors in Netlogo platform under three different flooding scenarios.

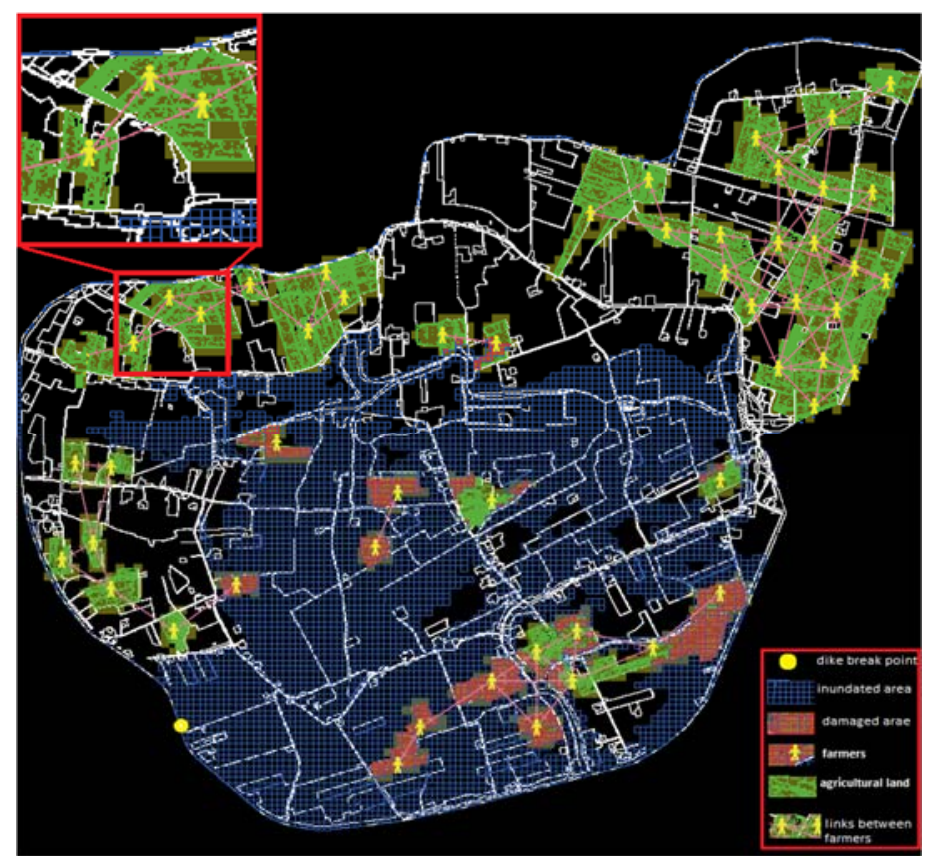

Figure 9. Damaged agricultural lands, farmers and their social network in first flooding scenario 
As seen in figure 9, some fields are inundated due to the first flood scenario (breach location: 160m from initial point) which in turn results in flood damages. For example, farmers living in the north-east part of island do not suffer from the flooding. However, each farmer interacts with his neighbors in his social network which are shown by pink lines (links). His social network includes all his neighbors who are living in the radius of $10 \mathrm{~m}$. Therefore, he can be aware of and influenced by decisions of those who belongs to his social network, even if he has not experienced by this flooding scenario (see zoom view in figure 9). Comparing inundated area, agricultural lands exposed to flooding and farmers in all three flooding scenarios (figure 9: breach location: 160m, figures 10: breach location: 205m, and figure 11: breach location in $239 \mathrm{~m}$ ) it can be seen that inundated areas differ for each flooding scenarios and it depends on the breach location which in turn results in different number and/or location of farmers experienced flood losses.

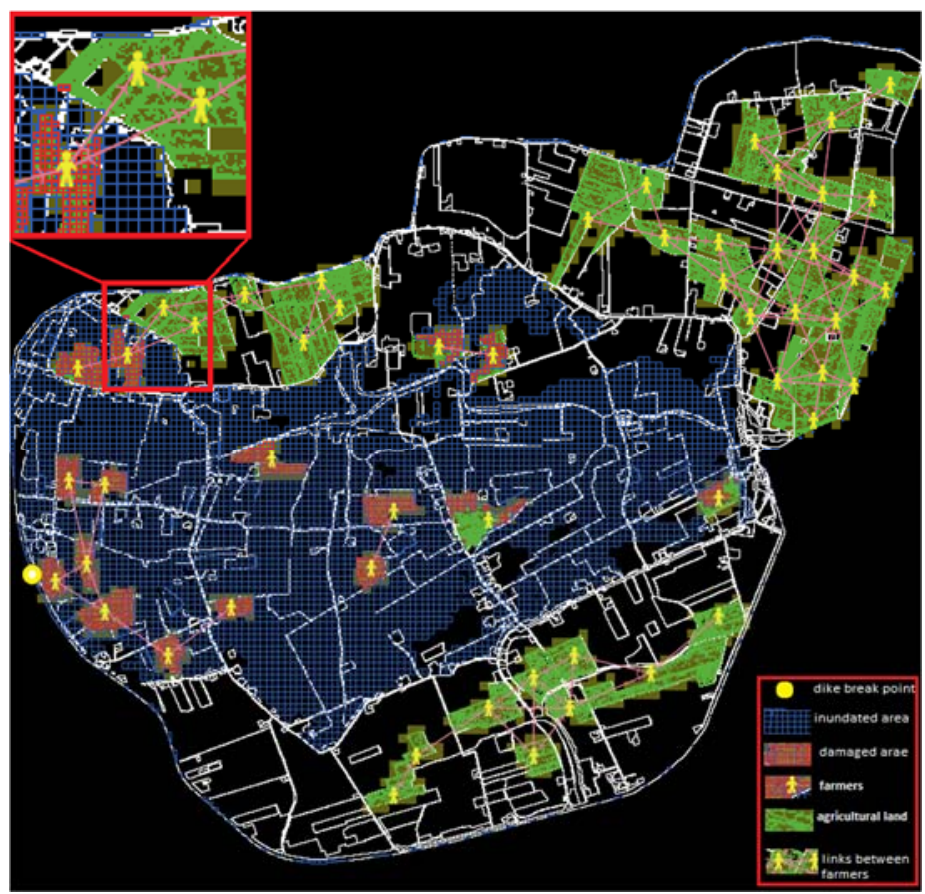

Figure 10. Damaged agricultural lands, farmers and their social network in second flooding scenario

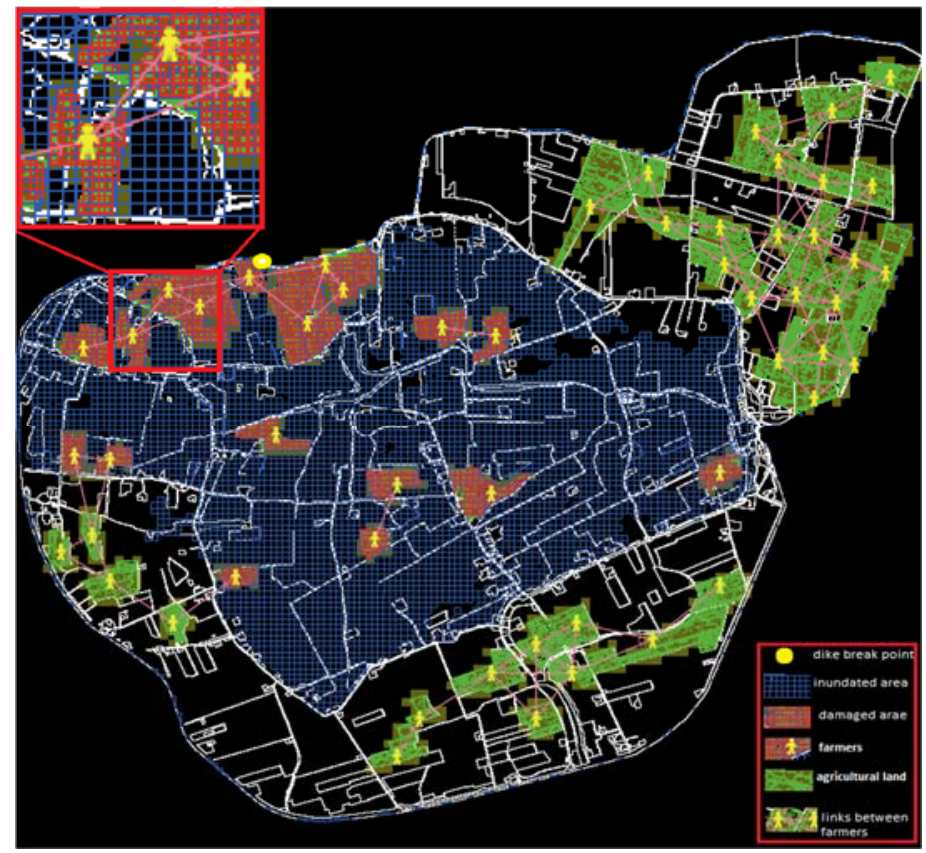

Figure 11. Damaged agricultural lands, farmers and their social network in third flooding scenario 
To make it clear, it is displayed by the zoom view in figure 9, 10, and 11. As illustrated, only farmers whose field is inundated are suffering form that flooding. However, those who interact with farmers in their neighborhood may also be impacted by neighbors in their next-year decision making.

\section{DISCUSSIONS AND CONCLUSIONS}

The developed Agent Based Model is a comprehensive approach to investigate human-flood interaction in terms of land use policies as non-structural measures in flooding areas. For this aim, it combines flood risk analysis and hydrological modeling integrating the social aspects of decision making which govern the behavioral rules of inhabitants living in these regions.

Farmers as the main entities of the model choose cropping patterns on their field based on factors affecting crop production such as climatic condition, land properties, and land management practices. Therefore, crop yields are computed in each time step in hydrological module with detailed information available as inputs.

In addition, farmers will be aware of the actual and expected flood damages in each time step which are provided by flood analysis module.

Taking all into account, they make decision for the next year based on not only crop yields and flood losses but also markets, and interactions in their social network. It is achieved through decision making module.

It is worthwhile to mention that the model combines the probabilistic nature of flood with decision making under uncertainty due to individual risk perception of flooding and unknown, time-varying variables such as prices and costs. It also seeks to go beyond pure maximization in individual decision making and equip agricultural agents with cognitive strategies in flooding area.

\section{ACKNOWLEDGMENTS}

This work is a part of the project “Application of Agent Based Model for human-flood interaction” which is funded by German Academic Exchange Service (DAAD).

\section{REFERENCES}

[1] IPCC. (2007): Climate change 2007: WG II: Impacts, Adaptation and Vulnerability, Chap. 6. Coastal systems and low lying areas. Inter governmental Panel on Climate Change (IPCC), Cambridge University Press.

[2] Kron W (2013): Coasts - the high risk areas of the world. Journal of Natural Hazards, Vol. 66, Issue 3, pp 1363-1382

[3] Kortenhaus A, Burzel A, Naulin M, Dassanayake DR, Oumeraci H, Jensen J, Wahl T, Mudersbach C, Gönnert G, Gerkensmeier B, Thumm S, and Ujeyl G (2011): Integrated risk analysis for extreme storm surges (XtremRisK), Proceedings 5th International Short Conference on Applied Coastal Research (SCACR), Aachen (Germany).

[4] Gilbert N and Troitzsch K (2005): Simulation for the Social Scientist, 2nd Edition, Milton Keynes: Open University Press.

[5] Bonabeau E (2002): Agent-based modeling: Methods and techniques for simulating human systems. Journal of PNAS, Vol.19, Issue 3, pp 7280-7287

[6] Mollona E (2008): Computer simulation in social sciences. Journal of management and government, Vol.12, pp. $205-211$

[7] Railsback S, Lytinen S, and Jackson S (2006): Agent-based simulation platforms: review and development recommendations. Journal Simulation, Vol. 82, Issue 9, pp 609-623.

[8] Wilensky U (1999): NetLogo. http://ccl.northwestern.edu/netlogo. Center for Connected Learning and Computer-Based Modeling. Northwestern University, Evanston, IL

[9] Wilensky U: http://ccl.northwestern.edu/netlogo/models/WolfSheepPredation 
[10] Linkola L, Clinton J, Andrews and Schuetze T (2013): An Agent Based Model of Houshold Water Use, Journal Water, Vol. 5, Issue 3, pp 1082-1100

[11] Individual (Agent)-Based modeling with NetLogo: A Predator-Prey example, NetLogo tutorial

[12] Chiacchio F, Pennisi M, Russo G, Motta S, and Pappalardo F (2014): Agent-Based Modeling of Immune system: NetLogo, a Promising Framework, Journal Biomed Research International

[13] Arnold JG, Srinivasan R, Muttiah RS, and Williams JR (1998): Large-area hydrologic modeling and assessment: Part I Model development. Journal of the American Water Resources Association, 34: pp. 73-89. doi: 10.1111/j.1752-1688.1998.tb05961.x

[14] Winchell M, Srinivasan R, Di Luzio M, and Arnold J (2013): ArcSWAT Interface for SWAT2012 - User's Guide. Texas, United States.

[15] Neitsch SL, Arnold JR, Kiniry JR, and Williams JR (2011): Soil and Water Assessment Tool Theoretical Documentation. Texas, United States.

[16] Bachmann D (2012): Beitrag zur Entwicklung eines Entscheidungsunterstützungssystems zur Bewertungund Planung von Hochwasserschutzmaßnahmen. Thesis (PhD). Aachen: Institut für Wasserbau und Wasserwirtschaft, RWTH Aachen; http://darwin.bth.rwth aachen.de/opus3/volltexte/2012/4043/ [Accessed 31.07.2012].

[17] Extension of the PROMAIDES software package to flood risk calculation for coastal regions within the HoRisK-project (2012): 6th Chinese-German Joint Symposium on Hydraulic and Ocean Engineering : CGJOINT2012; National Taiwan Ocean University Keelung, Seiten/Artikel-Nr: 227-235 